\title{
Tributación en servicios digitales
}

\section{Humberto Medrano Cornejo}

Abogado por la Pontificia Universidad Católica del Perú. Profesor de la Facultad de Derecho de la Pontificia Universidad Católica del Perú. Integrante de la comisión que redactó la Ley del Impuesto a la Renta y su reglamento.

(*) ADVOCATUS agradece a sus Miembros Asociados Lucy Ayme Salas, Mauricio Lavaud Allen y Allison Coloma Vallejos por su contribución en la elaboración de las preguntas de la presente entrevista. 


\section{RESUMEN:}

En la presente ocasión, ADVOCATUS tuvo la oportunidad de entrevistar a Humberto Medrano Cornejo, abogado peruano experto en derecho tributario. Ha sido presidente del Instituto Peruano de Derecho Tributario — IPDT, así como miembro fundador de la Fiscal International Association y Director del Instituto Latinoamericano de Derecho Tributario. A través de las siguientes líneas nos ofrece sus opiniones sobre la expansión digital y los retos para su tributación.

Palabras clave: economía digital, establecimiento permanente, OCDE, impuesto a la renta, impuesto general a las venta, SUNAT.

\section{ABSTRACT:}

ADVOCATUS had the opportunity to interview Humberto Medrano Cornejo, a Peruvian lawyer expert in tax law. He has been president of the Peruvian Institute of Tax Law — IPDT, as well as a founding member of the Fiscal International Association and Director of the Latin American Institute of Tax Law. Throughout the lines below, he offers us his opinions on digital expansion and the challenges for its taxation.

Keywords: digital economy, permanent establishment, OECD, income tax, general sales tax, Peruvian Tax Administration.

1. ¿Considera usted que la expansión de la economía digital a través de plataformas como lo son Spotify, Netflix, entre otras, cuya característica es ser un servicio digital prestado por sujetos no domiciliados ha generado un reto para la elaboración de un marco tributario en el Perú?

Sin duda se trata de un reto, pero que está referido no sólo a la legislación del Perú, sino que constituye una preocupación para muchos países, como lo prueban los múltiples eventos técnicos realizados en distintas partes para analizar el tratamiento impositivo a la economía digital, así como las recomendaciones al respecto de entidades como la Organización para la Cooperación y el Desarrollo Económico - OCDE. Es evidente que sobre esta materia la tecnología ha avanzado más rápidamente que el Derecho, pues en diversos lugares las regulaciones legales en este campo aún no han abarcado el régimen tributario que resulta aplicable.

2. ¿Qué conceptos -como por ejemplo, domicilio fiscal, habitualidad, establecimiento permanente, etc.- contemplados en la Ley de Impuesto a la Renta, Ley de Impuesto General a las Ventas y sus respectivos reglamentos, considera usted que deberían modificarse a fin de que servicios de streaming - como los brindados por Netflix, Spotify, etc.- puedan ser gravados con dichos impuestos?
Debe recordarse que conforme a nuestra Ley del Impuesto a la Renta —en adelante, "LIR" las personas domiciliadas tributan sobre su renta mundial, mientras que las no domiciliadas sólo deben hacerlo por sus rentas de fuente peruana. Tomando en cuenta que este tipo de servicios es prestado usualmente por empresas del exterior, parece claro que la preocupación del legislador debe centrarse en establecer cuándo la renta generada por estas operaciones debe calificar como de fuente nacional. Hace pocos años se incluyó dentro de ellas las producidas por los servicios digitales a través de Internet o cualquier otra red, cuando se utilicen económicamente, usen o consuman en el país. Es decir, básicamente, cuando sirven para el desarrollo de las actividades económicas de un contribuyente domiciliado perceptor de rentas de tercera categoría. En consecuencia, la regla no alcanza a los servicios que brindan Netflix, Uber, Spotify, entre otros, dirigidos a personas naturales que no perciben rentas provenientes de negocios.

Por otro lado, según la LIR, están gravados los servicios digitales prestados por empresas no domiciliadas con prescindencia de donde se utilicen económicamente, en la medida de que tales empresas cuenten con un establecimiento permanente —en adelante, "EP" — en el país; pero como esa condición no se presenta en la mayoría de ellas, se generan áreas de inafectación. Por lo tanto sería necesario - siguiendo a 
la OCDE - incluir el concepto de EP virtual, basado en la "presencia económica significativa" para que queden sujetas al tributo las rentas generadas en los países donde se encuentran los usuarios.

En cuanto al Impuesto General a las Ventas IGV, la ley considera como sujetos pasivos a quienes "utilicen en el país servicios prestados por no domiciliados", de modo que allí se comprende, entre otros, a los referidos usuarios que, por supuesto, tendrán derecho a utilizar su importe como crédito fiscal si - como señala la norma- tales servicios se destinan a operaciones gravadas con ese tributo.

3. Tomando en consideración el crecimiento en la economía digital y la expansión de plataformas streaming, iconsidera usted que es necesario implementar reformas en la LIR y la Ley del IGV, a fin de que el Estado peruano pueda percibir más ingresos fiscales?

Debido a que actualmente se discute sobre la manera más adecuada de gravar la economía digital, puede asegurarse que en el futuro inmediato las normas tributarias serán ajustadas para establecer la ubicación de la fuente y las circunstancias que deben darse para configurar el hecho imponible, tanto en el IR como para el IGV. La particularidad de estas operaciones obligará a especificar a quiénes debe considerarse contribuyentes y a quiénes - si fuera el caso- debe calificarse como responsables o como agentes de retención.

4. En el 2019, la Superintendencia Nacional de Aduanas y Administración Tributaria - SUNAT presentó una propuesta al Ministerio de Economía y Finanzas - MEF a fin de recaudar el IGV por los servicios brindados a plataformas digitales utilizados por personas naturales. Posteriormente, en setiembre de 2020, el Congreso presentó el Proyecto de Ley № 6181-2020-CR, a través del cual se busca concretar dicha tributación. En éste, se señaló como mecanismo recaudatorio a la retención vía tarjeta de crédito o dé- bito. En caso de que se optara por este mecanismo, ¿cuáles cree que serían las ventajas o desventajas de que sean los bancos los encargados de entregar el dinero al fisco peruano?

Desde luego, en el caso de usuarios personas naturales que por no ser comerciantes carecen de libros y registros contables, la fiscalización individual directa es casi imposible. Por ello, sería deseable comprender a los bancos en el mecanismo de recaudación, para lo cual es indispensable señalar con exactitud cuáles son los supuestos fácticos que deben ocurrir para que surja su obligación de intervenir desde el punto de vista fiscal. Como quiera que el uso de las tarjetas de crédito y de débito se ha generalizado en todos los ámbitos y se emplean en las más diversas transacciones, es fácil concluir que no en todos los casos estaríamos frente a pagos que constituyen retribución por servicios digitales. Eso significa que, en algunas ocasiones, para los bancos podría resultar complejo establecer si en los pagos efectuados por sus clientes hay lugar o no a la aplicación del tributo; lo que, eventualmente, podría llevar a cometer errores e incurrir en infracciones sancionables - lo que es necesario evitar-. Por lo tanto, las normas legales que pudieran expedirse sobre este extremo tendrían que ser meridianamente claras y puntualizar las hipótesis en que debe ocurrir tal intervención, a fin de que no se presenten conflictos entre esas entidades y la Administración.

5. De realizarse una reforma en la cual se opte por el mecanismo de retención vía tarjeta de crédito o débito a fin de retener el IR de empresas que brindan servicios digitales - como el de streaming-, ¿cree usted que la SUNAT posee suficientes recursos como para realizar fiscalizaciones respecto de la recaudación de estos impuestos a fin de supervisar su cumplimiento?

En cuanto a los recursos para la fiscalización, SUNAT podría cumplir sus labores sin mayor dificultad tratándose de usuarios dedicados a actividades mercantiles; pero es evidente que resultaría sumamente difícil llevar a cabo ins- 
pecciones respecto del íntegro de las transacciones realizadas por individuos no comerciantes y de allí la conveniencia de comprender a los bancos en el proceso.

Sin embargo, debe reiterarse que para ello se requiriría lograr la mayor precisión respecto de cuándo, dentro de cuáles parámetros y en qué tipo concreto de operaciones correspondería a las empresas financieras actuar en la etapa de recaudación.

\section{Tomando en consideración que la OCDE viene buscando la manera de abordar los desafíos fiscales de la economía digital de manera que se evite, entre otros as- pectos, la doble o nula imposición, ¿cuá- les serían sus recomendaciones respecto de este punto controvertido?}

Como ya se expresó, por ahora lo esencial es precisar cuándo constituye renta de fuente local el monto pagado a las empresas del exterior prestadoras de dichos servicios. Sin embargo, para evitar cargas fiscales inadecuadas, lo más conveniente es que nuestra legislación se ajuste a las medidas que se adopten a nivel internacional siguiendo los lineamientos de la
$\mathrm{OCDE}$, que está tratando de que los países que la integran lleguen a un acuerdo para imponer un tributo global a las multinacionales del área, cuya recaudación se distribuiría entre los fiscos de los países donde operan.

También pueden jugar un rol importante los convenios internacionales para evitar la doble imposición que, dicho sea de paso, el Perú debería suscribir con un mayor número de países y en los que podrían contemplarse medidas que eviten las dificultades a que se refiere la pregunta.

De otro lado, con el propósito de combatir la elusión, nuestra legislación ha venido regulando cada vez con más detalle lo relativo al valor de mercado de las transacciones en general y de manera más concreta al régimen de precios de transferencia que, precisamente, se aplica a las operaciones entre partes vinculadas y a las realizadas desde, hacia o a través de países no cooperantes o de baja o nula imposición. Además debe tenerse presente que varios países cuentan con convenios para el intercambio de información financiera, lo que en muchos casos permitiría determinar si se ha producido - o no- un exceso o un defecto en la aplicación del régimen tributario. 